\title{
Effects of light curing modes and ethanol-wet bonding on dentin bonding properties"
}

\author{
Mu-zi LI ${ }^{1,2}$, Jin-rui WANG ${ }^{1}$, Hong LIU $^{\dagger 11,2}$, Xia WANG ${ }^{1}$, Kang GAN ${ }^{1}$, Xiu-ju LIU ${ }^{1}$, De-li NIU ${ }^{1}$, Xiao-qing SONG ${ }^{1}$ \\ ('School and Hospital of Stomatology, Jilin University, Changchun 130021, China) \\ ( ${ }^{2}$ Jilin Provincial Key Laboratory of Tooth Development and Remodeling, Changchun 130021, China) \\ †E-mail: jdliuhong@163.com \\ Received Feb. 1, 2016; Revision accepted Apr. 25, 2016; Crosschecked Aug. 8, 2016
}

\begin{abstract}
Objective: This study explored the effects of different light curing modes and ethanol-wet bonding on dentin bonding strength and durability. Methods: A total of 54 molars were randomly divided into three groups: Single Bond 2, Gluma Comfort Bond, and N-Bond. Based on the three light-curing modes and presence or absence of ethanol pretreatment, the samples were assigned to six subgroups: high-light mode, ethanol pretreatment+high-light mode, soft-start mode, ethanol pretreatment+soft-start mode, standard mode, and ethanol pretreatment+standard mode. All samples were bonded with resin based on the experimental groups. After $24 \mathrm{~h}$ and 6 months of water storage, a universal testing machine was used to measure microtensile bond strength. Scanning electron microscopy (SEM) was applied to observe mixed layer morphology. Results: The 24-h and 6-month microtensile bond strengths of the ethanol pretreatment groups were significantly higher than those of the non-ethanol pretreatment groups at the same light modes $(P<0.05)$. With or without ethanol pretreatment, the microtensile bond strengths of the high-light modes were significantly lower than those of the soft-start modes and standard modes $(P<0.05)$. The microtensile bond strengths of samples from the 6-month water storage group significantly decreased compared with those of samples from the 24-h water storage group $(P<0.05)$. The soft-start groups and standard groups formed better mixed layers than the high-light mode groups, whereas the ethanol pretreatment groups formed more uniform mixed layers than those without ethanol pretreatment. Conclusions: Ethanol-wet bonding technique, soft-start, and standard modes could improve dentin bonding properties.
\end{abstract}

Key words: Light curing mode, Soft-start, Ethanol-wet bonding, Scanning electron microscopy (SEM), Bonding strength

http://dx.doi.org/10.1631/jzus.B1600055

CLC number: R783.3

\section{Introduction}

With continuing in-depth research on the adhesive properties and the increase in people's aesthetic requirements, improving the quality and durability of the bonding interface has become an urgent problem in dentin bonding (Sadek et al., 2010; Guimarães

\footnotetext{
¿Corresponding author

* Project supported by the Science and Technology Research Project of the Education Department of Jilin Province of China (No. (2015)527)

(D) ORCID: Hong LIU, http://orcid.org/0000-0001-5532-2531

(c) Zhejiang University and Springer-Verlag Berlin Heidelberg 2016
}

et al., 2012; Li et al., 2012). Although the two-step total-etch technique can achieve high bond strength, there are problems of high technical sensitivity, uncontrollable interface moisture and poor durability. Since the dentin bonding strength is generated after the formation of micro-mechanical retention by the resin monomer in the etched collagen fiber network, the quality of the hybrid layer (Urapepon, 2014) is directly related to the strength and durability, and therefore a uniform and dense hybrid layer can obtain better bonding effect (Marshall et al., 2010). The moisture content and the cured extent of the adhesive resin on the dentin surface will affect the quality of 
the mixed layer, and further study of these factors will contribute to the ability to form a good hybrid layer, thus contributing to achieving an ideal bonding effect.

Introduced in the early 1990 s, the water-wet bonding technique by Pashley et al. (2007) is a method of keeping dentin moist to prevent the collapse of the collagen fibers after etching, which will help the resin monomers penetrate the collagen fiber network. However, water-wet bonding has difficulty in controlling moisture and in standardization, and excessive moisture in the bonding interface often leads to hydrophobic resin monomers not completely penetrating, which results in the negative phenomenon of affecting dentin bonding properties such as incomplete polymerization, micro-phase separation, and nanoleakage (Tay and Pashley, 2003; Cunha et al., 2007). Therefore Pashley et al. (2007) proposed an ethanol-wet bonding technique where ethanol displacing water in dentin not only can reduce the moisture content of the dentin surface, but also can make it easier for adhesive resin to penetrate the dentin collagen fiber network, thereby facilitating the formation of a dense and homogeneous mixture of a hydrophobic layer to increase its bond strength and durability.

In addition, the resin binder is a highly flowable composite resin, and its main drawback is polymerization shrinkage during light curing (Osiewicz et al., 2015). If shrinkage stress during the polymerization process is greater than the adhesive force in the bonding interface, it will generate gaps in the bonding interface and the material inside. Thus, the polymerization shrinkage of a composite resin has a lot of negative effects on clinical applications, such as microleakage, edge color, fracture of teeth or restorative materials, post-operative sensitivity, and secondary caries (Bouschlicher et al., 2000; Marghalani, 2014). To facilitate clinical operation and shorten treatment time, high-powered light-emitting diode (LED) light units came into being. Although high intensity irradiation can improve the conversion of the resin monomer and enhance the mechanical properties of the material, the shrinkage stress and elastic modulus of the resin matrix are increased because of the shortening of the time to reach the gel point of the composite resin (Suh et al., 1999), which leads to reduced adhesion properties. Hardan et al. (2009) proposed the soft-start light curing mode where the initial light intensity has a lower irradiation, which can make the resin flow sufficiently to compensate for the volume shrinkage generated by the polymerization reaction, and then a high-light intensity is used in irradiation to improve the conversion rate of the resin monomer to a maximum extent (Malhotra and Kundabala, 2010). Thus light intensity and light curing modes that directly affect polymerization reaction and the degree of curing, also affect the resin monomer penetrating the dentin collagen fiber network in forming the mixed layer, thereby influencing the dentin bond performance.

In this study, the ethanol-wet bonding technique and light curing modes will apply to the fifth generation total-etch adhesive systems to explore their impact on dentin bonding strength and durability. There were three hypotheses as follows: (1) ethanol would not affect the performance of dentin bonding; (2) different light curing modes would not have different effects on dentin bonding properties; (3) the impacts of three adhesives on bonding properties would exhibit no difference.

\section{Materials and methods}

\subsection{Grouping}

A total of 54 third molars without caries were collected. Informed consent was obtained from the donors of the teeth and approved by the Ethics Committee of Jilin University (China). Under running water, a low-speed IsoMet saw (MTI Ltd., USA) was used to cut enamel from the occlusal surface of the molar to expose shallow dentin. To simulate the clinical dentin smear layer's interface, the dentin surface was polished for $60 \mathrm{~s}$ using 600 -grit $\mathrm{SiC}$ paper under running water. All samples were randomly divided into the following three groups based on different adhesives, namely, Single Bond 2 (3M ESPE Ltd., St. Paul, MN, USA), Gluma Comfort Bond (Heraeus Kulze Ltd., Hanau, Germany), and Tetric ${ }^{\circledR}$ N-Bond (Ivoclar Vivadent AG Ltd., Schaan, Liechtenstein).

Based on the three different light curing modes of Dr.'s Light Curing Light (Good Doctors Company, Korea) and with or without ethanol pretreatment, the samples were assigned to six subgroups: Group A, high-light mode; Group B, ethanol pretreatment + 
high-light mode; Group C, soft-start mode; Group D, ethanol pretreatment+soft-start mode; Group E, standard mode; Group F, ethanol pretreatment+ standard mode. Light modes and exposure time are shown in Table 1.

Table 1 Instructions for light mode

\begin{tabular}{lcc}
\hline Light mode & Time (s) & Profile \\
\hline High-light & 10 & $\begin{array}{c}\text { Continuous energy output power of } \\
1000 \mathrm{~mW} / \mathrm{cm}^{2} \text { for } 10 \mathrm{~s}\end{array}$ \\
Soft-start & 10 & $\begin{array}{l}\text { Output power is raised gradually } \\
\text { from } 400 \text { to } 1200 \mathrm{~mW} / \mathrm{cm}^{2} \text { in } 5 \mathrm{~s}, \\
\text { and power remains at } 1000 \mathrm{~mW} / \mathrm{cm}^{2} \\
\text { during the next } 5 \mathrm{~s} \\
\text { Continuous energy output power of } \\
500 \mathrm{~mW} / \mathrm{cm}^{2} \text { for } 20 \mathrm{~s}\end{array}$ \\
\hline
\end{tabular}

Light intensity as is claimed by the manufacturer

\subsection{Bonding procedure}

The dentin surface was etched for $15 \mathrm{~s}$ by $37 \%$ $(0.37 \mathrm{~g} / \mathrm{ml})$ phosphoric acid gel (Scientific Pharmaceuticals Inc., Pomona, CA, USA) and then rinsed for $30 \mathrm{~s}$ with distilled water. The cotton ball was placed on the edge of tooth to suck the excess water. An appropriate amount of adhesive was gently smeared on the moist dentin surface for $10 \mathrm{~s}$ using a small brush and lightly dried for $5 \mathrm{~s}$. Subsequently, the adhesive surface was irradiated under different light curing modes according to the experimental groups. For the ethanol pretreatment groups, the etched dentin surface was inserted into $99.7 \%$ ethanol for $2 \mathrm{~min}$, and excess ethanol was absorbed by a dry cotton ball. After the curing of adhesives, four layers of Z350 A2 resin (3M ESPE, USA) were stacked up to a height of $4 \mathrm{~mm}$. Each layer was cured individually with the corresponding light mode for $20 \mathrm{~s}$. After bonding, all samples were stored in distilled water at $37^{\circ} \mathrm{C}$ for $24 \mathrm{~h}$.

\subsection{Measurement of specimens for microtensile bond strength}

Under running water, a saw was used perpendicular to the bonding interface to cut the tooth with a cross-sectional area of $0.9 \mathrm{~mm} \times 0.9 \mathrm{~mm}$. Cylindrical specimens of approximately $6.0 \mathrm{~mm}$ in length were obtained. "No-crack" specimens were randomly divided into two groups ( $n=10$ each group). A group of samples was immediately used for the microtensile bond strength test, and the bonding interface area was measured and recorded with a Vernier caliper $(0-150$,
Tricle Brand, Shanghai, China) with an accuracy of $0.01 \mathrm{~mm}$. Another group of samples was stored in double distilled water at $37^{\circ} \mathrm{C}$ for 6 months.

The microtensile fixture was placed on a universal testing machine (AG-Xplus $10 \mathrm{KN}$, Shimadzu, Japan) with a pre-load of $5 \mathrm{~N}$, a sensor of $500 \mathrm{~N}$, and a crosshead speed of $1 \mathrm{~mm} / \mathrm{min}$ until the specimens fractured. The microtensile bond strengths were calculated by the formula: $\sigma_{\mathrm{s}}=F /(b \times d)$, where $\sigma_{\mathrm{s}}$ is the microtensile bond strength (MPa), $F$ is the fracture tension (N), $b$ is the sample width (mm), and $d$ is the sample thickness $(\mathrm{mm})$. The fracture type of the interfaces was observed by a stereomicroscope (SZX16, Olympus, Japan) at the magnification of $30 \times$. The fracture types were divided into the following four types: (1) interfacial fracture occurring in the interface of dentin and resin; (2) cohesive fracture of dentin occurring within the dentin; (3) cohesive fracture of resin occurring within the resin; and (4) mixed fracture with interfacial fracture and cohesive fracture.

SPSS 17.0 (SPSS Inc., Chicago, IL, USA) was used for data analysis. Two-way analysis of variance (ANOVA) and multiple comparisons with Tukey's test (5\%) were used to analyze microtensile results. A Fisher test was performed to analyze the fracture type of the interfaces.

\subsection{Observation of specimens using scanning electron microscopy}

Following the aforementioned steps, 18 extracted teeth bonded with resin were prepared, and were cut into $4.0 \mathrm{~mm} \times 4.0 \mathrm{~mm} \times 1.5 \mathrm{~mm}$. An intermediate portion of samples was etched by $37 \%$ phosphoric acid gel and then immersed in $5.25 \%$ sodium hypochlorite (Fuchen Chemical Reagent Factory, Tianjin, China) for $10 \mathrm{~min}$. After the water rinse, samples were treated using $50.0 \%, 70.0 \%, 90.0 \%$, and $99.7 \%$ ethanol for $15 \mathrm{~min}$ each, and soaked overnight in $99.7 \%$ ethanol. The hybrid layer was observed by field emission scanning electron microscopy (SEM; XL30, Japan) with an accelerating voltage of $10 \mathrm{kV}$.

\section{Results}

\subsection{Microtensile results}

Table 2 shows the results of 24-h microtensile bond strengths, and Table 3 shows the results of 
6-month microtensile bond strengths. Under the same experimental conditions, the strengths of Single Bond 2 (SB), Gluma Comfort Bond (GB), and Tetric ${ }^{\circledR}$ N-Bond (NB) did not show a significant difference $(P>0.05)$. The 24-h and 6-month microtensile bond strengths of the ethanol pretreatment groups were significantly higher $(P<0.05)$ than those of the non-ethanol pretreatment groups with the same light modes. With or without ethanol pretreatment, the microtensile bond strengths of the high-light modes were significantly lower $(P<0.05)$ than those of the soft-start and standard modes at $24 \mathrm{~h}$ and 6 months of water storage. The microtensile bond strengths of the standard modes and soft-start modes showed no statistical difference $(P>0.05)$.

Compared with $24 \mathrm{~h}$, the microtensile bond strength in 6 months of each group was significantly decreased $(P<0.05)$, but the decline in the microtensile bond strengths between the three adhesives showed no significant difference $(P>0.05)$. The strengths of Groups A-F fell by an average of $54.89 \%$, $40.07 \%, 40.00 \%, 25.00 \%, 38.29 \%$, and $24.89 \%$, respectively. Thus, the decline in the ethanol pretreatment groups was obviously lower than that in the nonethanol pretreatment groups, and the decline in the soft-start modes and standard mode groups was far less than that in the high-light mode groups.

\subsection{Fracture type observations}

The fracture types of 24-h microtensile specimens are shown in Fig. 1. The fracture types of 6-month microtensile specimens are shown in Fig. 2. Fisher's exact test showed that the fracture types of all groups were mainly interfacial fracture, and cohesive and mixed fractures were rare. We observed no significant differences among the groups $(P>0.05)$.

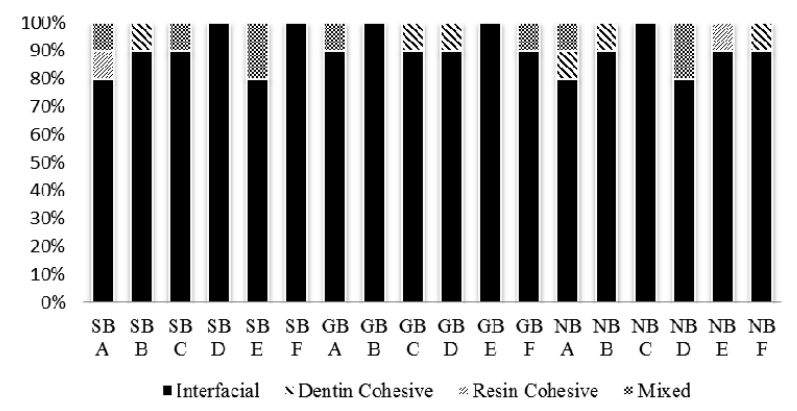

Fig. 1 Fracture types of 24-h microtensile specimens A: high-light mode; B: ethanol pretreatment+high-light mode; C: soft-start mode; D: ethanol pretreatment+soft-start mode; E: standard mode; F: ethanol pretreatment+standard mode; SB: Single Bond 2; GB: Gluma Comfort Bond; NB: Tetric ${ }^{\circledR}$ N-Bond. The same for the following Figs. 2 and 3

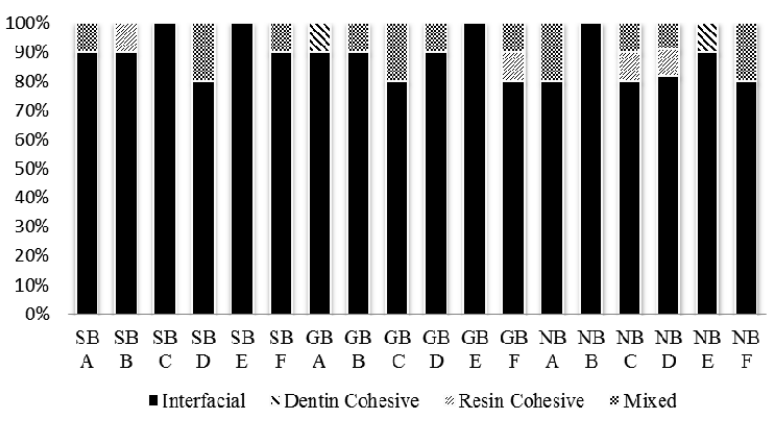

Fig. 2 Fracture types of 6-month microtensile specimens

Table 2 Mean microtensile bond strengths with standard division of $24 \mathrm{~h}$ groups $(n=10)$

\begin{tabular}{|c|c|c|c|c|c|c|}
\hline \multirow{3}{*}{ Adhesive } & \multicolumn{6}{|c|}{ Mean microtensile bond strength (MPa) } \\
\hline & \multicolumn{2}{|c|}{ High-light } & \multicolumn{2}{|c|}{ Soft-start } & \multicolumn{2}{|c|}{ Standard } \\
\hline & Null & Ethanol & Null & Ethanol & Null & Ethanol \\
\hline SB & $41.07 \pm 3.90^{\mathrm{Aa}}$ & $53.44 \pm 5.31^{\mathrm{Ab}}$ & $51.79 \pm 4.41^{\mathrm{Ab}}$ & $65.03 \pm 4.78^{\mathrm{Ac}}$ & $52.06 \pm 4.24^{\mathrm{Ab}}$ & $67.27 \pm 4.44^{\mathrm{Ac}}$ \\
\hline GB & $37.88 \pm 3.35^{\mathrm{Aa}}$ & $50.03 \pm 3.59^{\mathrm{Ab}}$ & $49.15 \pm 3.91^{\mathrm{Ab}}$ & $62.80 \pm 4.32^{\mathrm{Ac}}$ & $49.19 \pm 3.78^{\mathrm{Ab}}$ & $63.75 \pm 4.33^{\mathrm{Ac}}$ \\
\hline NB & $38.11 \pm 3.78^{\mathrm{Aa}}$ & $50.32 \pm 4.25^{\mathrm{Ab}}$ & $49.24 \pm 3.63^{\mathrm{Ab}}$ & $62.93 \pm 4.40^{\mathrm{Ac}}$ & $50.50 \pm 4.14^{\mathrm{Ab}}$ & $64.62 \pm 4.79^{\mathrm{Ac}}$ \\
\hline
\end{tabular}

The same superscripted letters indicate no significant differences $(P>0.05)$. a-c indicate statistically significant differences between different treatment methods (within the same adhesives). A-C indicate statistically significant differences between different adhesives (within the same treatment). SB: Single Bond 2; GB: Gluma Comfort Bond; NB: Tetric ${ }^{\circledR}$ N-Bond. The same for the following Table 3

Table 3 Mean microtensile bond strengths with standard division of 6 months groups $(n=10)$

\begin{tabular}{|c|c|c|c|c|c|c|}
\hline \multirow{3}{*}{ Adhesive } & \multicolumn{6}{|c|}{ Mean microtensile bond strength (MPa) } \\
\hline & \multicolumn{2}{|c|}{ High-light } & \multicolumn{2}{|c|}{ Soft-start } & \multicolumn{2}{|c|}{ Standard } \\
\hline & Null & Ethanol & Null & Ethanol & Null & Ethanol \\
\hline SB & $18.07 \pm 3.05^{\mathrm{Aa}}$ & $32.07 \pm 3.41^{\mathrm{Ab}}$ & $31.28 \pm 3.52^{\mathrm{Ab}}$ & $49.49 \pm 4.34^{\mathrm{Ac}}$ & $32.06 \pm 3.15^{\mathrm{Ab}}$ & $51.09 \pm 4.22^{\mathrm{Ac}}$ \\
\hline GB & $16.73 \pm 3.12^{\mathrm{Aa}}$ & $29.40 \pm 3.27^{\mathrm{Ab}}$ & $29.18 \pm 3.04^{\mathrm{Ab}}$ & $46.68 \pm 4.24^{\mathrm{Ac}}$ & $30.72 \pm 3.65^{\mathrm{Ab}}$ & $47.03 \pm 4.62^{\mathrm{Ac}}$ \\
\hline NB & $17.97 \pm 2.99^{\mathrm{Aa}}$ & $30.70 \pm 3.41^{\mathrm{Ab}}$ & $29.65 \pm 3.52^{\mathrm{Ab}}$ & $46.92 \pm 3.72^{\mathrm{Ac}}$ & $30.85 \pm 3.48^{\mathrm{Ab}}$ & $48.85 \pm 4.59^{\mathrm{Ac}}$ \\
\hline
\end{tabular}




\subsection{Scanning electron microscopy}

Fig. 3 shows that the high-light mode groups formed short and uneven resin tags and bubbly uneven mixed layers, whereas the soft-start groups and standard groups formed longer and more uniform resin tags and relatively continuous and uniform mixed layers. The ethanol pretreatment groups formed much longer and more uniform resin tags and more compact and uniform mixed layers than those without ethanol pretreatment. Resin tags and mixed layers formed by the three adhesives were similar.

\section{Discussion}

In modern bonding technology, the dentin bonding interface frequently has incomplete polymerization, micro-phase separation and nanoleakage, which will adversely affect the performance of the dentin bonding (Cunha et al., 2007). Traditional water-wet bonding makes the collapsed collagen fiber network resume a fluffy state, but excess moisture in the bonding interface leads to phase separation and nanoleakage. However, the ethanol-wet bonding
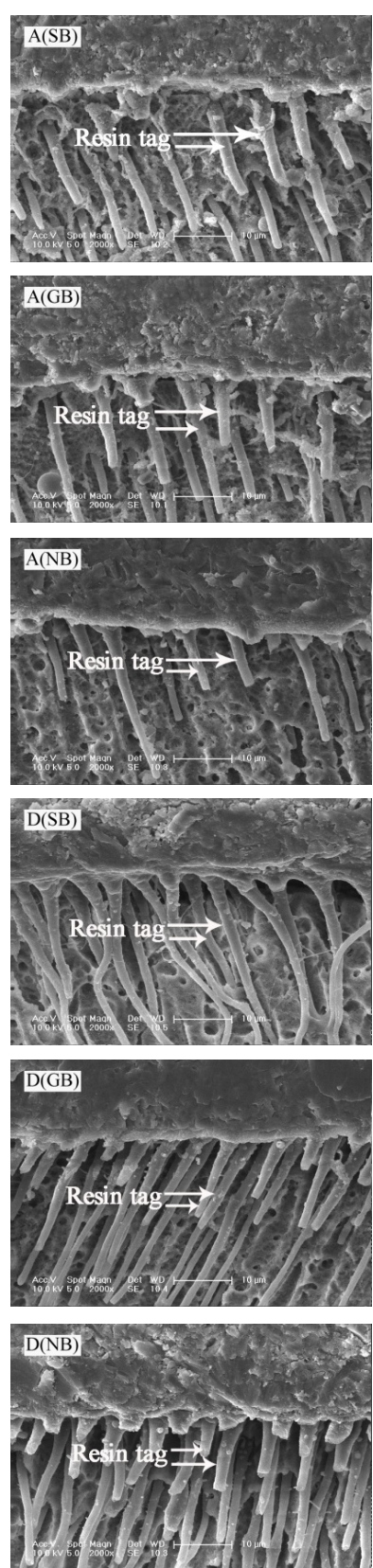
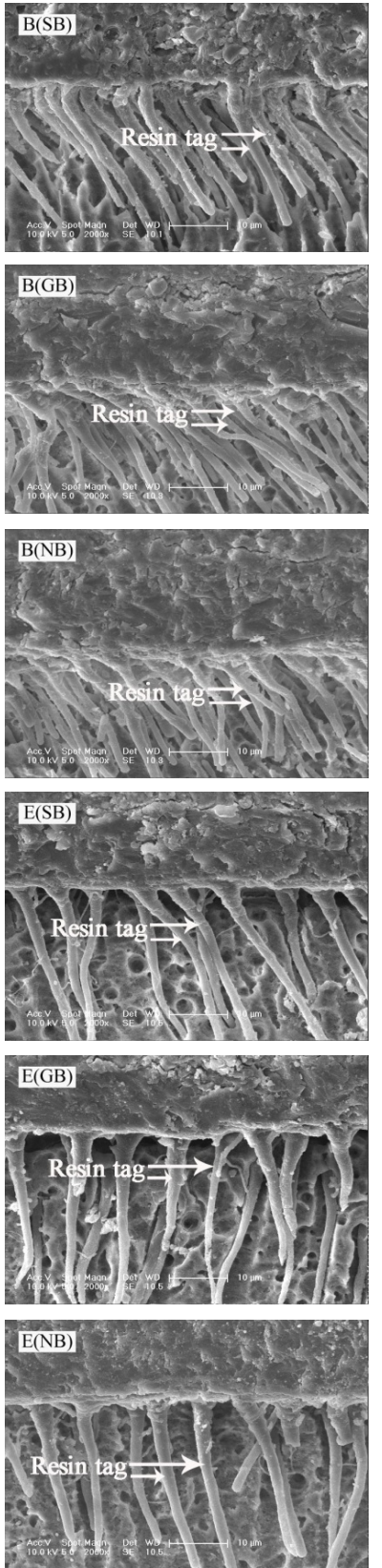
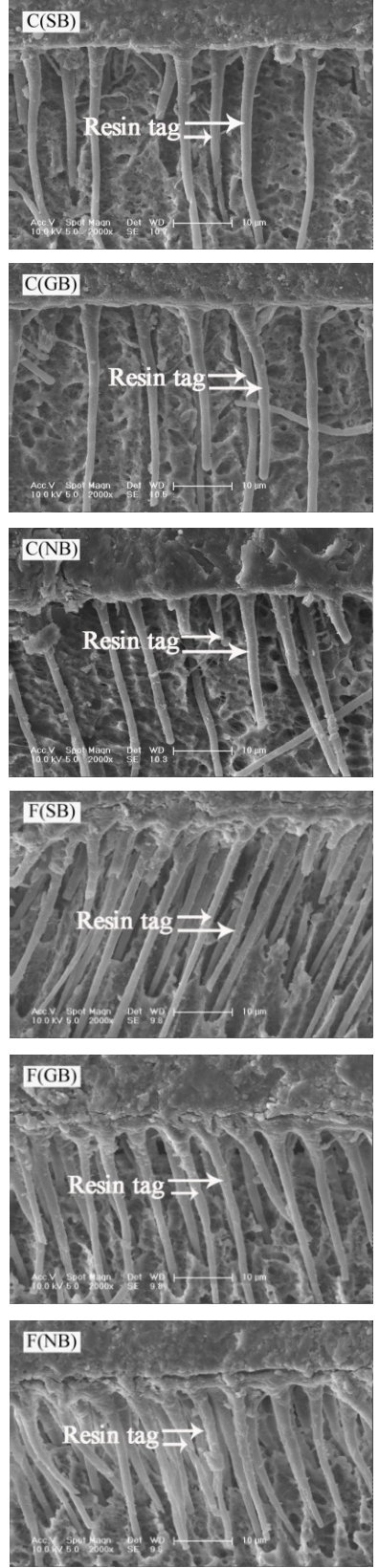

Fig. 3 SEM micrographs of Groups A-F 
technique can solve this problem, since ethanol can replace the water in demineralized dentin, occupy gaps between collagen fibers, and reduce dentin hydrophilic, and most of the hydrophobic resin monomers can be soluble in alcohol, so they can better penetrate the dentin collagen fibers and dentinal tubules (Nishitani et al., 2006; Li et al., 2012; Sartori et al., 2015). In addition, ethanol in demineralized dentin can cause transverse shrinkage of collagen fibers that increases gaps between collagen fibers and decreases the collagen matrix hydrophilicity, which provides advantageous locations for subsequent infiltration of hydrophobic resin to form a homogeneous dense hybrid layer in order to obtain good bonding properties (Ahn et al., 2015; Yang et al., 2016).

Nishitani et al. (2006) suggested that the bonding strength of ethanol-wet bonding is higher than that of water-wet bonding. In our experiment, the 24- $h$ and 6-month microtensile bond strengths of the ethanol pretreatment groups are significantly higher $(P<0.05)$ than those of the non-ethanol pretreatment groups at the same light modes. With the same processing method, 6-month microtensile bond strength decreases significantly $(P<0.05)$, indicating that the degradation of the bonding interface is inevitable in the water environment. The 6-month microtensile test not only shows bonding strength, but also reflects bonding durability. With the same light modes, the decline in microtensile bond strength of the ethanol pretreatment groups is significantly less than that of the non-ethanol pretreatment groups, indicating that ethanol-wet bonding technique will help to improve the durability of the bonding interface. SEM shows that ethanol groups can form more uniform and longer resin tags, and a more uniformly continuous hybrid layer than non-ethanol groups, which is consistent with the microtensile bond strength results, and the dentin bonding property is closely related to the quality of the hybrid layer and the number and length of resin tags. The results deny the first hypothesis, so ethanol-wet bonding technique can form a good dentin bonding interface, thereby significantly improving dentin bonding strength and durability of the totaletch adhesive.

Light curing intensity and pattern can influence the degree of curing of the resin binder, thus affecting its bonding properties (Haenel et al., 2015). Fahmy et al. (2009) reports that the pulse mode and fast mode have similar performance, so we chose high-light mode, soft-start mode, and normal-light mode instead of pulse mode in this experiment. To explore the effects of light modes on dentin bonding properties clearly, the irradiation time of the three modes is selected to be approximately of the same total light energy (Rueggeberg, 1998).

Light curing resin binder can incur a polymerization shrinkage reaction under the irradiation of certain wavelengths of visible light. This polymerization shrinkage will cause bonding internal stress increases that trigger microcracks in the bonding interface and materials, and these gaps may lead to microleakage and reduction in bond strength within the bonding interface (Giachetti et al., 2006). This is the main reason for the failure of repair materials (Mohammad et al., 2006). High-light intensity can improve the depth of curing and degree of conversion of the resin monomer to enhance mechanical properties of the composite resin (Nalcaci et al., 2005; Alto et al., 2006; Filho et al., 2008). Since curing speed is proportional to the square root of light intensity (Visvanathan et al., 2007), the curing speed of the high-light mode is faster and this can produce a larger polymerization shrinkage and internal stress within the bonding interface. It is not conducive to penetration and stretch of monomer into the dentin collagen fiber network, thus forming shorter resin tags and an asymmetrical mixed layer. In addition, it will make the oxygen inhibition layer thin on the adhesive surface (Kim et al., 2006) and make dentinal tubule fluid increasingly penetrate the adhesive surface (Breschi et al., 2008), thus affecting its bonding performance.

The soft-start mode is to start with a lower light intensity that extends the flow time of the resin to offset polymerization shrinkage stress, and then irradiate with a higher light intensity to fully cure the resin. Some scholars believe that the soft-start mode cannot reduce polymerization stress and microleakage, and that it has no significant effect on improving marginal adaptation in the bonding interface and degree of conversion of the resin monomer (Bouschlicher et al., 2000; Fleming et al., 2007). Too high or too low initial intensity cannot achieve a good curing effect (Marghalani, 2014), so the initial light intensity of the soft-start mode in our experiment is 
$400 \mathrm{~mW} / \mathrm{cm}^{2}$. Cunha et al. (2007) reported that the soft-start mode did not reduce the degree of conversion, but led to lower shrinkage stress and higher bond strength, which demonstrated the correlation with shrinkage stress and bond strength. When the adhesive surface is irradiated with a lower-intensity irradiation, phototropism shrinkage stress generated by the resin monomer is lower (Tseng et al., 2007). It is conducive to penetration and stretch of monomer into the dentin collagen fiber network to form longer and thicker resin tags and the dense and uniform mixed layer, and thus its microtensile bond strength will be higher. The experimental results show that with the same pretreatment, whether the water storage is $24 \mathrm{~h}$ or 6 months, the microtensile bond strength of the high-light model group is lower than those of the soft-start group and the standard mode group. The SEM shows that high-light mode groups formed short and uneven resin tags and bubbly uneven mixed layers, whereas the soft-start groups and standard groups formed longer and more uniform resin tags and relatively continuous and uniform mixed layers. It is consistent with the above views and denies the second assumption. So, different light curing modes have different effects on dentin bonding properties.

Microtensile results show that, in the same experimental conditions, the strengths of $\mathrm{SB}, \mathrm{GB}$, and $\mathrm{NB}$ groups at $24 \mathrm{~h}$ and 6 months water storage have no significant difference $(P>0.05)$, and the declines of the microtensile bond strengths of three adhesives from $24 \mathrm{~h}$ to 6 months also show no significant difference. Microtensile bond strengths of different adhesives are different due to the different compositions and resin fillers. Single Bond 2 with the higher monomer concentration can form the thicker mixing layers after evaporation of solvents, and the component of polyalkenoic acid copolymer can enhance chemical combination with structures (Hashimoto et al., 2002). Silica nanofillers in Single Bond 2 can not only more easily penetrate the collagen fiber network, but also reduce volume shrinkage during polymerization, which can increase bond strength.

\section{Conclusions}

Dentin bonding performance is closely related to the quality of the mixed layers, and ethanol pre- treatment can significantly improve the performance of total-etch dentin bonding systems and the quality of the mixed layer. Soft-start mode and standard mode can obtain better dentin bonding properties and quality of the mixed layer. The three total-etch adhesives have no significant difference on microtensile results or the quality of the mixed layers.

\section{Compliance with ethics guidelines}

Mu-zi LI, Jin-rui WANG, Hong LIU, Xia WANG, Kang GAN, Xiu-ju LIU, De-li NIU, and Xiao-qing SONG declare that they have no conflict of interest.

All procedures followed were in accordance with the ethical standards of the responsible committee on human experimentation (institutional and national) and with the Helsinki Declaration of 1975, as revised in 2008 (5). Informed consent was obtained from all patients for being included in the study.

\section{References}

Ahn, J., Jung, K.H., Son, S., et al., 2015. Effect of additional etching and ethanol-wet bonding on the dentin bond strength of one-step self-etch adhesives. Restor. Dent. Endod., 40(1):68-74. http://dx.doi.org/10.5395/rde.2015.40.1.68

Alto, M., Vieira, R., Guimarães, J.G.A., et al., 2006. Depth of cure of dental composites submitted to different lightcuring modes. J. Appl. Oral Sci., 14(2):71-76. http://dx.doi.org/10.1590/S1678-77572006000200002

Bouschlicher, M.R., Rueggeberg, F.A., Boyer, D.B., 2000. Effect of stepped light intensity on polymerization force and conversion in a photoactivated composite. J. Esthet. Dent., 12(1):23-32. http://dx.doi.org/10.1111/j.1708-8240.2000.tb00195.x

Breschi, L., Mazzoni, A., Ruggeri, A., et al., 2008. Dental adhesion review: aging and stability of the bonded interface. Dent. Mater., 24(1):90-101. http://dx.doi.org/10.1016/j.dental.2007.02.009

Cunha, L.G., Alonso, R.C.B., Pfeifer, C.S.C., et al., 2007. Modulated photoactivation methods: influence on contraction stress, degree of conversion and push-out bond strength of composite restoratives. J. Dent., 35(4):318-324. http://dx.doi.org/10.1016/j.jdent.2006.10.003

Fahmy, N., Naguib, H., Guindy, J.E., 2009. Effect of lightemitting diode (LED) curing modes on resin/dentin bond strength. J. Prosthodont., 18(8):670-675. http://dx.doi.org/10.1111/j.1532-849X.2009.00502.x

Filho, D.N., Poskus, L.T., Guimarães, J.G.A., et al., 2008. Degree of conversion and plasticization of dimethacrylatebased polymeric matrices: influence of light-curing mode. J. Oral Sci., 50(3):315-321. http://dx.doi.org/10.2334/josnusd.50.315

Fleming, G.J.P., Cara, R.R., Palin, W.M., et al., 2007. Cuspal movement and microleakage in premolar teeth restored 
with resin-based filling materials cured using a 'soft-start' polymerisation protocol. Dent. Mater., 23(5):637-643. http://dx.doi.org/10.1016/j.dental.2006.06.002

Giachetti, L., Scaminaci Russo, D., Bambi, C., et al., 2006. A review of polymerization shrinkage stress: current techniques for posterior direct resin restorations. J. Contemp. Dent. Pract., 7(4):79-88.

Guimarães, L.A., Almeida, J.C.F., Wang, L., et al., 2012. Effectiveness of immediate bonding of etch-and-rinse adhesives to simplified ethanol-saturated dentin. Braz. Oral Res., 26(2):177-182. http://dx.doi.org/10.1590/S1806-83242012000200015

Haenel, T., Hausnerová, B., Steinhaus, J., et al., 2015. Effect of the irradiance distribution from light curing units on the local micro-hardness of the surface of dental resins. Dent. Mater., 31(2):93-104. http://dx.doi.org/10.1016/j.dental.2014.11.003

Hardan, L.S., Amm, E.W., Ghayad, A., et al., 2009. Effect of different modes of light curing and resin composites on microleakage of Class II restorations-Part II. Odontostomatol. Trop., 32(126):29-37.

Hashimoto, M., Ohno, H., Kaga, M., et al., 2002. Fractured surface characterization: wet versus dry bonding. Dent. Mater., 18(2):95-102. http://dx.doi.org/10.1016/S0109-5641(01)00023-9

Kim, J.S., Choi, Y.H., Cho, B.H., et al., 2006. Effect of light-cure time of adhesive resin on the thickness of the oxygen-inhibited layer and the microtensile bond strength to dentin. J. Biomed. Mater. Res. B Appl. Biomater., 78(1): 115-123. http://dx.doi.org/10.1002/jbm.b.30463

Li, F., Liu, X.Y., Zhang, L., et al., 2012. Ethanol-wet bonding technique may enhance the bonding performance of contemporary etch-and-rinse dental adhesives. J. Adhes. Dent., 14(2):113-120. http://dx.doi.org/10.3290/j.jad.a21853

Malhotra, N., Kundabala, M., 2010. Light-curing considerations for resin-based composite materials: a review. Part I. Compend. Contin. Educ. Dent., 31(7):498-505.

Marghalani, H.Y., 2014. The influence of different lightcuring modes on microleakage of posterior resin composites. J. Adhes. Sci. Technol., 28(2):136-150. http://dx.doi.org/10.1080/01694243.2013.827095

Marshall, S.J., Bayne, S.C., Baier, R., et al., 2010. A review of adhesion science. Dent. Mater., 26(2):e11-e16. http://dx.doi.org/10.1016/j.dental.2009.11.157

Mohammad, K.A., Hamdoon, M.G., Rasheed, A.L.M., 2006. Effects of curing modes of light emitting diode on shear bond strength of resin composite. Al-Rafidain Dent. J., 8(18):168-176.

Nalcaci, A., Kucukesmen, C., Uludag, B., 2005. Effect of high-powered LED polymerization on the shear bond strength of a light-polymerized resin luting agent to ceramic and dentin. J. Prosthet. Dent., 94(2):140-145. http://dx.doi.org/10.1016/j.prosdent.2005.05.001
Nishitani, Y., Yoshiyama, M., Donnelly, A.M., et al., 2006. Effects of resin hydrophilicity on dentin bond strength. $J$. Dent. Res., 85(11):1016-1021. http://dx.doi.org/10.1177/154405910608501108

Osiewicz, M.A., Werner, A., Pytko-Polonczyk, J., et al., 2015. Contact- and contact-free wear between various resin composites. Dent. Mater., 31(2):134-140. http://dx.doi.org/10.1016/j.dental.2014.11.007

Pashley, D.H., Tay, F.R., Carvalho, R.M., et al., 2007. From dry bonding to water-wet bonding to ethanol-wet bonding. A review of the interactions between dentin matrix and solvated resins using a macromodel of the hybrid layer. Am. J. Dent., 20(1):7-20.

Rueggeberg, F., 1998. Contemporary issues in photocuring. Compend. Contin. Educ. Dent. Suppl., 25:S4-S15.

Sadek, F.T., Braga, R.R., Muench, A., 2010. Ethanol wetbonding challenges current anti-degradation strategy. $J$. Dent. Res., 89(12):1499-1504. http://dx.doi.org/10.1177/0022034510385240

Sartori, N., Peruchi, L.D., Phark, J.H., et al., 2015. Permeation of intrinsic water into ethanol- and water-saturated, monomer-infiltrated dentin bond interfaces. Dent. Mater., 31(11):1385-1395. http://dx.doi.org/10.1016/j.dental.2015.08.159

Suh, B.I., Feng, L., Wang, Y., et al., 1999. The effect of the pulse-delay cure technique on residual strain in composites. Compend. Contin. Educ. Dent., 20(2):4-12.

Tay, F.R., Pashley, D.H., 2003. Have dentin adhesives become too hydrophilic? J. Can. Dent. Assoc., 69(11):726-731.

Tseng, W.Y., Chen, R.S., Wang, J.L., et al., 2007. Effects on microstrain and conversion of flowable resin composite using different curing modes and units. J. Biomed. Mater. Res. B Appl. Biomater., 81(2):323-329. http://dx.doi.org/10.1002/jbm.b.30668

Urapepon, S., 2014. Degree of conversion of resin composite cured by light through a translucent fiber posts. $J . A d v$. Prosthodont., 6(3):194-199. http://dx.doi.org/10.4047/jap.2014.6.3.194

Visvanathan, A., Ilie, N., Hickel, R., et al., 2007. The influence of curing times and light curing methods on the polymerization shrinkage stress of a shrinkage-optimized composite with hybrid-type prepolymer fillers. Dent. Mater., 23(7):777-784. http://dx.doi.org/10.1016/j.dental.2006.06.019

Yang, H., Guo, J., Deng, D., et al., 2016. Effect of adjunctive application of epigallocatechin-3-gallate and ethanol-wet bonding on adhesive-dentin bonds. J. Dent., 44:44-49. http://dx.doi.org/10.1016/j.jdent.2015.12.001

\section{中文概要}

题 目: 不同光固化模式和乙醇湿粘接对牙本质粘结性能
的影响 
目 的: 探究不同光固化模式和乙醇湿粘接对牙本质粘结 强度及耐久性的影响, 为临床应用提供理论指导。

创新点: 率先将乙醇湿粘接技术和不同光固化模式有机结 合，成功筛选出了提高牙本质粘结性能的有效策 略。

方 法: 将 Single Bond 2 (SB) 组、Gluma Comfort Bond (GB) 组和 N-Bond (NB) 组分别分为 6 个亚组: 高光照射模式、乙醇预处理+高光照射模式、软 启动照射模式、乙醇预处理+软启动照射模式、 标准照射模式和乙醇预处理+标准照射模式。按
照分组粘结, 水储 24 小时和 6 个月后, 应用万 能测试机分别检测微拉伸强度, 体视显微镜观察 微拉伸试件断裂类型和扫描电镜观察混合层形 态。

结 论: 乙醇湿粘接技术可以改善混合层质量, 从而提高 其粘结强度和改善粘结耐久性; 软启动光照模式 和标准光照模式可以形成更好的混合层质量, 获 得更高的牙本质粘结强度和更好的粘结耐久性。

关键词: 光照模式; 软启动; 乙醇湿粘接; 粘结强度; 扫 描电子显微术 